\title{
A drug utilization and pharmacoeconomic study of anti-diabetic drugs prescribed to type 2 diabetes mellitus patients visiting the medicine out- patient department of a tertiary care hospital of north India
}

\author{
Amandeep Singh ${ }^{1}$, Shakti Bala Dutta ${ }^{1}$, Amit Varma ${ }^{2}$, Mirza Atif Beg ${ }^{1}$, Hitender Kumar ${ }^{1}$, \\ Amanjot Kaur ${ }^{1}$
}

\begin{abstract}
${ }^{1}$ Department of Pharmacology,
${ }^{2}$ Department of Medicine, Shri Guru Ram Rai Institute of

Medical and Health Sciences, Patel Nagar, Dehradun,

Uttarakhand, India
\end{abstract}

Received: 29 June 2016

Accepted: 05 July 2016

\section{*Correspondence to:}

Dr. Amandeep Singh,

Email: angad.aman@gmail.com

Copyright: (C) the author(s), publisher and licensee Medip Academy. This is an openaccess article distributed under the terms of the Creative Commons Attribution NonCommercial License, which permits unrestricted noncommercial use, distribution, and reproduction in any medium, provided the original work is properly cited.

\begin{abstract}
Background: Type 2 diabetes mellitus (T2DM) patients require anti-diabetic drugs on chronic basis, frequent monitoring of blood glucose levels and a number of laboratory investigations, all of which result in significant economic burden on the diabetes patients and the world economies. The purpose of this study was to analyse the prescribing pattern to highlight the current approaches to the rational use of anti-diabetic drugs in T2DM patients visiting the medicine out-patient department, and to calculate the economic burden of different antidiabetic therapies prescribed to patients with T2DM in a tertiary care hospital of north India.
\end{abstract}

Methods: This prospective study included T2DM patients visiting the outpatient department of medicine of a tertiary care hospital of Uttarakhand, India. Prescriptions of patients diagnosed as cases of T2DM were analysed as per the WHO drug use indicators. For pharmacoeconomic evaluation, the cost variation of different anti-diabetic therapies was compared using the cost-effectiveness analysis method.

Results: 273 prescriptions from 148 men and 125 women were analysed. 805 drugs were prescribed to the patients with an average of 2.95 per encounter: 494 anti-diabetic drugs with an average of 1.81 drugs per patient, and 311 for comorbid conditions. Of the 494 anti-diabetic drugs, $75.1 \%$ were oral anti-diabetic (OAD) agents and 24.9\% were insulin's. Metformin (209) and insulin aspart (42) were the most prescribed $\mathrm{OAD}$ and insulin, respectively. The pharmacoeconomic analysis included 138 patients. The cost per unit $(1 \mathrm{mg} / \mathrm{dl})$ reduction in fasting blood glucose was lowest with glipizide and metformin combination (INR 10.46) and highest with insulin degludec and insulin aspart combination (INR 217.38). The average total direct cost of therapy for two months was INR $2244.39 \pm 2745.05$ (INR 362.88 to INR 10806). $86.63 \%$ of the average total direct cost of therapy was attributed to anti-diabetic agents.

Conclusions: Metformin was the most common OAD agent and insulin aspart was the most common injectable anti-diabetic drug prescribed in patients with T2DM. The newer anti-diabetic drugs sitagliptin and newer insulin analogues were also prescribed to a great extent. Overall, the prescribing trend was rational to a great extent and had improved since the earlier study in the same institute. The most cost-effective anti-diabetic therapy was combination therapy of glipizide and metformin. The cost of diabetes management is high, especially for insulin therapy.

Keywords: Diabetes mellitus, Anti-diabetic drugs, Drug utilization, Pharmacoeconomic, Cost effectiveness analysis

\section{INTRODUCTION}

Type 2 diabetes mellitus (T2DM) is the commonest form of diabetes (responsible for $>90 \%$ cases of diabetes) affecting around 422 million people in the world, and more than $80 \%$ of diabetes deaths occur in low- and middle-income countries. ${ }^{1}$ The treatment of patients with T2DM involves diet, exercise and lifestyle modifications. Those not controlled are put on oral anti-diabetic (OAD) agents, the most commonly used being sulfonylurea's and 
metformin. ${ }^{2}$ Also, a number of new drugs have been added in the last few years to the pool of anti-diabetic drugs including dipeptidyl peptidase 4 (DPP-4) inhibitors, glucagon-like peptides-1 (GLP-1) receptor agonists, insulin analogues, etc.

Drug utilization research is defined by World Health Organization (WHO) as "marketing, distribution, prescription and use of drugs in a society, with special emphasis on the resulting medical, social and economic consequences". It is an essential part of pharmacoepidemiology as it describes the extent, nature and determinants of drug exposure. ${ }^{3}$ Drug utilization review is defined as authorized, structured and continuing program that reviews, analyses and interprets the pattern of drug use against pre-determined standards. ${ }^{4}$ The drug utilization study thus identifies the problems that arises from the drug usage in healthcare delivery system and highlights the current approaches to the rational use of drugs.

T2DM patients usually require lifelong management with anti-diabetic medicines, leading to immense economic burden on the diabetes patient and the world economies as a whole. Also, the healthcare costs for patients with diabetes are more than double the costs for people without diabetes. ${ }^{5}$ The specialized field of health economics which helps to know the economic burden of disease management to the patient is known as pharmacoeconomics. ${ }^{6}$ Pharmacoeconomics has been defined as the description and analysis of the cost of drug therapy to health care systems and society. ${ }^{7}$ It adopts and applies the principles and methodologies of health economics to help measure the cost and outcome or benefit of pharmaceutical products and services. ${ }^{6}$

Four main types of pharmacoeconomic evaluation methods are used: cost minimization analysis (CMA), cost benefit analysis (CBA), cost effectiveness analysis (CEA), and cost utility analysis (CUA). CEA compares the cost differences in terms of money between two or more therapies whose outcomes can be measured in the same natural units. It helps to identify a preferred choice of treatment among possible alternatives based on the cost and clinical benefit. Result of cost effectiveness analysis are expressed as an average cost-effectiveness ratio (ACER) which is calculated as healthcare cost divided by benefit or clinical outcome, or as an Incremental cost-effectiveness ratio (ICER) which is calculated as the additional cost that a treatment alternative imposes over another treatment divided by the additional effect, benefit, or outcome it provides. ${ }^{6,8,9}$

This study was thus designed to analyze the drug utilization pattern of various anti-diabetic drugs in T2DM patients visiting the medicine out-patient department, and to do the pharmacoeconomic analysis to find out the most cost-effective anti-diabetic therapy prescribed to patients with T2DM in a tertiary care hospital of north India.

\section{METHODS}

\section{Study population}

This study comprised of T2DM patients over 18 years of age visiting the out-patient department of medicine at Shri Mahant Indiresh Hospital, attached to Shri Guru Ram Rai Institute of Medical and Health Sciences, Patel Nagar, Dehradun, India. Patients of either sex who were willing to give written informed consent were included in the study. Prescriptions of T2DM patients containing case history and treatment details were included in the study. The exclusion criteria for the study were: patients with type 1 diabetes, patients in congestive heart failure or advanced coronary artery disease, significant gastrointestinal disease and hepatic impairment, females on oral contraceptives or hormone replacement therapy, patients having advanced nephropathy, proliferative retinopathy and neuropathy. Patients who fulfilled the inclusion and exclusion criteria were enrolled in the study.

\section{Study design}

This prospective study was conducted by the department of pharmacology, Shri Guru Ram Rai Institute of Medical and Health Sciences, Patel Nagar, Dehradun, India in association with the department of medicine at Shri Mahant Indiresh Hospital, Patel Nagar, Dehradun, India over one year from April 2015 to March 2016. Prior to the initiation of study, the study protocol and informed consent form were got approved by the institutional ethics committee of the institute.

Prescriptions of patients diagnosed as cases of T2DM were analyzed based on the following WHO drug use indicators: average number of drugs per prescription, dosage form of drugs, number of fixed dose combinations (FDCs) prescribed, frequency of drug administration, duration of therapy, whether the drugs are prescribed in generic or proprietary name(s), number of drugs prescribed from WHO Model List of Essential Medicines, 19th edition, 2015 (WHO-EML 2015); also the number of drugs from national list of essential medicines (NLEM) 2015 of India. ${ }^{10,11,12}$ WHO recommends that while calculating the number of drugs in a prescription, all the active ingredients in a FDC or multidrug formulations should be counted as one and not separately. However, in this study while evaluating the data for the total number of drugs prescribed, each active ingredient in a FDC was counted as a separate entity.

For pharmacoeconomic evaluation, cost effectiveness analysis method was used. The healthcare cost of antidiabetic therapies prescribed for T2DM causing reduction in fasting blood glucose (FBG) levels by $1 \mathrm{mg} / \mathrm{dl}$ was taken into consideration. The healthcare costs included the direct medical costs which comprised of cost of antidiabetic drugs, physician charges and laboratory charges. Drugs other than anti-diabetic agents were not included in 
cost effectiveness analysis. The cost of the drug prescribed were consulted from local pharmacy and checked from Drug today October-December 2015, and current index of medical specialties (CIMS) JanuaryApril 2016. ${ }^{13,14}$ For change in FBG levels, the patients were followed for eight weeks and the levels of FBG were recorded at baseline and after eight weeks. Results of cost effectiveness analysis were calculated as

Average cost-effectiveness ratio $(\mathrm{ACER})=($ Healthcare cost during eight weeks of therapy)/(Mean reduction in FBG levels over eight weeks). ${ }^{8,9}$

The cost variations of different anti-diabetic therapies in terms of ACER were then compared.

\section{Statistics}

All anti-diabetic drugs and their drug classes were recorded. The data were tabulated as mean \pm standard deviation. Results for drug utilization pattern were analysed in terms of percentage using Microsoft excel software. For pharmacoeconomic analysis, results were analysed using ANOVA (one-way), using Graphpad Instat software version 3.0. A p-value $<0.05$ was considered statistically significant.

\section{RESULTS}

A total of 273 patients were enrolled in the study. The baseline demographic and laboratory characteristics of the patients included in the study are given in Table 1.

Table 1. Baseline demographic and laboratory characteristics of the patients.

\begin{tabular}{|ll|}
\hline Baseline characteristics & Value \\
\hline Age group (years) & $\mathrm{n}(\%)$ \\
\hline $21-30$ & $10(3.66 \%)$ \\
\hline $31-40$ & $42(15.38 \%)$ \\
\hline $41-50$ & $101(36.99 \%)$ \\
\hline $51-60$ & $82(30.04 \%)$ \\
\hline$>60$ & $38(13.92 \%)$ \\
\hline Mean Age (years) & $50.56 \pm 13.33$ \\
\hline Male/female & $\begin{array}{l}\mathrm{n}=148(54.21 \%) / \mathrm{n}=125 \\
(45.79 \%)\end{array}$ \\
\hline $\begin{array}{l}\text { Average duration of } \\
\text { diabetes }\end{array}$ & $6.31 \pm 2.54$ years \\
\hline FBG (mg/dl) & $157.21 \pm 51.64$ \\
\hline
\end{tabular}

All values expressed in mean $\pm \mathrm{SD}$, except sex; SD, standard deviation.

\section{Drug utilization pattern}

WHO drug use indicators were analysed from prescriptions of all 273 patients. The study included 148 (54.21\%) men and 125 (45.79\%) women (Table 1). The mean age of the study participants was $50.56 \pm 13.33$ years, and majority $(n=183 ; 67.03 \%)$ of the patients were in the age group of 41-60 years. The average duration of diabetes was $6.31 \pm 2.54$ years. Most common co-morbid disorder was hypertension $(n=97)$, followed by acid peptic disease $(n=29)$, dyslipidemia $(n=23)$, rheumatoid arthritis $(n=11)$, and schizophrenia $(n=5)$.

580 drug formulations containing 805 active ingredients were prescribed with an average of 2.95 per encounter (range from 1-7 drugs) (Table 2). Of the 805 drugs, 494 $(61.37 \%)$ were anti-diabetic drugs and 311 (38.64\%) were for co-morbid conditions. An average of 1.81 antidiabetic drugs (active ingredients) was prescribed per patient. Of the 494 anti-diabetic drugs, 75.1\% (371) were OAD agents and 24.9\% (123) were insulin's. As shown in Table 3 and 4, biguanides (209; 76.56\%) were the most prescribed drug class, and the least prescribed were thiazolidinedione's $(8 ; 2.93 \%)$. Metformin was the most favoured OAD $(209 ; 76.56 \%)$ followed by glimepiride $(82 ; 30.04 \%)$, and least prescribed was glipizide (5, $1.83 \%)$. Rapid acting insulin's $(48 ; 17.58 \%$ ) were the most used insulin class, and the most prescribed insulin was insulin aspart $(42 ; 15.38 \%)$ and least given was insulin lispro $(6 ; 2.2 \%)$.

Table 2: Number of drugs prescribed per patient.

\begin{tabular}{|ll|}
\hline Number of drugs & $\mathbf{n}(\boldsymbol{\%})$ \\
\hline 1 & $24(8.79 \%)$ \\
\hline 2 & $67(24.54 \%)$ \\
\hline 3 & $121(44.32 \%)$ \\
\hline 4 & $37(13.55 \%)$ \\
\hline 5 & $12(4.39 \%)$ \\
\hline 6 & $8(2.93 \%)$ \\
\hline 7 & $4(1.46 \%)$ \\
\hline
\end{tabular}

$58(21.24 \%)$ patients were prescribed anti-diabetic drugs as monotherapy and $215 \quad(78.75 \%)$ were given combination therapy. 194 were prescribed FDCs (149 dual therapy OADs, 6 triple therapy OADs, and 49 dual therapy insulin's) and 21 were prescribed non-FDC combination therapy (dual therapy of both insulin and OAD). Most common drug used as monotherapy was metformin $(n=43)$ and most prescribed drugs in combination therapy were glimepiride and metformin $(n=76)$. FDC of insulin aspart and insulin degludec $(n=33)$ was the most prescribed insulin combination.

Anti-hypertensive drugs $(128 ; 41.16 \%)$ were the most common drugs prescribed from among the 311 drugs for conditions other than diabetes, followed by antacids (46; $14.79 \%)$, multivitamins $(35 ; 11.25 \%)$, analgesics (34; $10.93 \%)$, anti-platelet drugs $(27 ; 8.68 \%)$, statins (19; $6.11 \%)$, nitrates $(7 ; 2.25 \%)$, anti-psychotics $(5 ; 1.61 \%)$, and miscellaneous drugs $(10 ; 3.21 \%)$. Most common drugs prescribed other than anti-diabetic drugs were ramipril $(n=35)$, and pantoprazole $(n=34)$; the most common FDC was of telmisartan and hydrochlorothiazide $(n=18)$. 
Table 3: Anti-diabetic drugs prescribing pattern.

\begin{tabular}{|ll|}
\hline Anti-diabetic drugs & n (\%) \\
\hline Metformin & $43(15.75 \%)$ \\
\hline Voglibose & $9(3.3 \%)$ \\
\hline Pioglitazone & $2(0.73 \%)$ \\
\hline Insulin aspart & $2(0.73 \%)$ \\
\hline Insulin lispro & $2(0.73 \%)$ \\
\hline Metformin+sitagliptin & $58(21.24 \%)$ \\
\hline Metformin+glimepiride & $76(27.84 \%)$ \\
\hline Metformin+glipizide & $5(1.83 \%)$ \\
\hline Metformin+glimepiride+pioglitazone & $6(2.2 \%)$ \\
\hline Insulin degludec+insulin aspart & $33(12.09 \%)$ \\
\hline Insulin regular+insulin isophane & $16(5.86 \%)$ \\
\hline Metformin+insulin glargine & $10(3.66 \%)$ \\
\hline Metformin+insulin aspart & $7(2.56 \%)$ \\
\hline Metformin+insulin lispro & $4(1.46 \%)$ \\
\hline
\end{tabular}

Table 4: Frequency of prescribing of anti-diabetics drugs.

\begin{tabular}{|c|c|}
\hline Anti-diabetic drugs & n $(\%)$ \\
\hline Biguanides & $209(76.56 \%)$ \\
\hline Metformin & $209(\mathbf{7 6 . 5 6} \%)$ \\
\hline Sulfonylureas & $87(31.87 \%)$ \\
\hline Glimepiride & $82(30.04 \%)$ \\
\hline Glipizide & $5(1.83 \%)$ \\
\hline $\begin{array}{l}\text { Dipeptidyl peptidase-4 } \\
\text { Inhibitors }\end{array}$ & $58(21.24 \%)$ \\
\hline Sitagliptin & $58(21.24 \%)$ \\
\hline$\alpha$-glucosidase Inhibitors & $9(3.3 \%)$ \\
\hline Voglibose & $9(3.3 \%)$ \\
\hline Thiazolidinedione's & $8(2.93 \%)$ \\
\hline Pioglitazone & $8(2.93 \%)$ \\
\hline Rapid Acting Insulin's & $48(17.58 \%)$ \\
\hline Insulin Lispro & $6(2.2 \%)$ \\
\hline Insulin Aspart & $42(15.38 \%)$ \\
\hline Short Acting Insulin & $16(5.86 \%)$ \\
\hline Regular insulin & $16(5.86 \%)$ \\
\hline Intermediate Acting Insulin's & $16(5.86 \%)$ \\
\hline Isophane insulin & $16(5.86 \%)$ \\
\hline Long Acting Insulin's & $43(15.75 \%)$ \\
\hline Insulin Glargine & $10(3.66 \%)$ \\
\hline Insulin Degludec & $33(12.09 \%)$ \\
\hline
\end{tabular}

Table 5 shows the analyses of prescriptions for antidiabetic drugs as per the WHO drug prescribing indicators. Dosage form of drugs was given in $68.13 \%$ prescriptions. For the 294 anti-diabetic drug formulations prescribed, most common route used was oral (220, $74.83 \%$ ), followed by subcutaneous route $(74,25.17 \%)$. $10.88 \%$ (32) of the anti-diabetics drugs were prescribed by generic name, and $89.12 \%$ (262) were prescribed by proprietary or brand name. Metformin was the only drug prescribed by generic name. Frequency of drug administration and duration were given in $88.23 \%$ and $60.07 \%$ of prescriptions, respectively. $23.44 \%$ (64) of anti-diabetic drugs prescribed were from WHO-EML 2015, and 27.21\% (80) from NLEM 2015.

\section{Pharmacoeconomic evaluation}

For cost effectiveness analysis, only 138 patients (79 men, 59 women) of the total 273 patients were included as the remaining patients were either lost to follow-up, needed hospitalization or incomplete data was available 150 anti-diabetic drug formulations containing 237 active ingredients were prescribed with an average of 1.72 per prescription. Most of the patients received combination therapy $(97 ; 70.29 \%)$, and the most common FDC was of metformin and glimepiride (33) (Table 6). For monotherapy (41), most common drug used was metformin (34).

\section{Table 5: WHO drug prescribing indicators for anti-} diabetic drugs.

\begin{tabular}{|ll|}
\hline WHO drug use indicators & $\mathbf{n}(\%)$ \\
\hline $\begin{array}{l}\text { Average number of drugs per } \\
\text { prescription }\end{array}$ & 2.95 \\
\hline $\begin{array}{l}\text { Average number of anti-diabetic } \\
\text { drugs per prescription }\end{array}$ & 1.81 \\
\hline Dosage form of drugs & $186(68.13 \%)$ \\
\hline $\begin{array}{l}\text { Number of fixed dose combinations } \\
\text { (FDC) prescribed }\end{array}$ & $194(71.06 \%)$ \\
\hline Frequency of drug administration & $241(88.23 \%)$ \\
\hline Duration of therapy & $164(60.07 \%)$ \\
\hline Drugs prescribed by generic name & $32(10.88 \%)$ \\
\hline $\begin{array}{l}\text { Drugs prescribed by proprietary } \\
\text { name(s) }\end{array}$ & $262(89.12 \%)$ \\
\hline $\begin{array}{l}\text { Drugs prescribed from WHO model } \\
\text { list of essential medicines }\end{array}$ & $64(23.44 \%)$ \\
\hline $\begin{array}{l}\text { Drugs prescribed from national essentia } \\
\text { medicine list (NLEM) }\end{array}$ & $80(27.21 \%)$ \\
\hline
\end{tabular}

As shown in Table 6, the maximum mean reduction of FBG was seen with FDC of regular insulin and isophane insulin $(54.8 \mathrm{mg} / \mathrm{dl})$ among the injectables and with FDC of glimepiride $2 \mathrm{mg}$ and metformin $(35.78 \mathrm{mg} / \mathrm{dl})$ among the OADs; and the lowest decrease in FBG was seen with pioglitazone $(21.85 \mathrm{mg} / \mathrm{dl})$ among the OADs and insulin aspart $(32.67 \mathrm{mg} / \mathrm{dl})$ among the insulins.

The cost per unit $(1 \mathrm{mg} / \mathrm{dl})$ reduction in FBG (ACER) was highest with FDC of insulin degludec and insulin aspart (INR 217.38) and lowest with FDC of glipizide and metformin (INR 10.46). Among the OADs, the ACER was highest with voglibose (INR 62.79). Among the injectables, the FDC of regular insulin and isophane insulin (INR 23.93) was most economical in causing reduction in FBG. The average dose for all insulins came to $30 \mathrm{IU}$ per day, and was taken for calculation of the cost of insulin therapy. The average total direct cost for two month management on OPD basis for T2DM was INR 2244.39 \pm 2745.05 (INR 362.88 for metformin and glimepiride combination, to INR 10806 for insulin 
degludec and insulin aspart combination). In majority of the patients $(93,67.39 \%)$, the cost was between INR 300 to INR 1000. The maximum expenditure was on antidiabetic agents and consumables like injection (86.63\%), followed by laboratory charges $(7.13 \%)$, and physician charges accounted for $6.24 \%$ of the average total direct cost (Figure 1). Statistically non-significant difference $(p=0.972)$ was seen in average total direct cost per unit reduction in FBG (ACER) between different treatment groups.

Table 6: Cost effectiveness analysis of anti-diabetic drugs.

\begin{tabular}{|lllll|}
\hline Drug & $\mathbf{n}(\%)$ & $\begin{array}{l}\text { Average total } \\
\text { direct cost (INR) }\end{array}$ & $\begin{array}{l}\text { Average } \\
\text { decrease in FBG } \\
\text { (mg/dl) }\end{array}$ & $\begin{array}{l}\text { ACER (Cost / unit } \\
\text { decrease in FBG) }\end{array}$ \\
\hline Metformin (500 mg) & $11(7.97 \%)$ & 401.7 & 24.05 & 16.70 \\
\hline Metformin (1000 mg) & $23(16.67 \%)$ & 503.4 & 31.92 & 15.77 \\
\hline Voglibose & $4(2.89 \%)$ & 1380 & 22.01 & 62.79 \\
\hline Pioglitazone & $2(1.45 \%)$ & 911.7 & 21.85 & 41.72 \\
\hline Glipizide+metformin & $3(2.17 \%)$ & 362.88 & 34.69 & 10.46 \\
\hline Glimepiride (1 mg)+metformin & $20(14.49 \%)$ & 597 & 27.26 & 21.9 \\
\hline Glimepiride (2 mg)+metformin & $13(9.42 \%)$ & 948.6 & 35.78 & 26.51 \\
\hline Sitagliptin+metformin & $19(13.77 \%)$ & 1692 & 31.04 & 54.51 \\
\hline Glimepiride+metformin+pioglitazone & $2(1.45 \%)$ & 807 & 30.7 & 26.29 \\
\hline Insulin lispro+metformin & $2(1.45 \%)$ & 1619.7 & 39.19 & 41.33 \\
\hline Insulin glargine+metformin & $5(3.62 \%)$ & 5021.7 & 50.18 & 100.07 \\
\hline Insulin aspart & $1(0.72 \%)$ & 3600.6 & 32.67 & 110.21 \\
\hline Insulin degludec+insulin aspart & $21(15.22 \%)$ & $10806 *$ & 49.71 & 217.38 \\
\hline Insulin regular+insulin isophane & $7(5.07 \%)$ & 1311.3 & 54.8 & 23.93 \\
\hline Insulin aspart+metformin & $5(3.62 \%)$ & 3702.3 & 48.06 & 77.03 \\
\hline
\end{tabular}

*All Insulin's are available commercially as $10 \mathrm{ml}$ vials containing $100 \mathrm{IU} / \mathrm{ml}$, except for Insulin Degludec + Insulin Aspart (available as $3 \mathrm{ml}$ vial containing $100 \mathrm{IU} / \mathrm{ml}$ ).

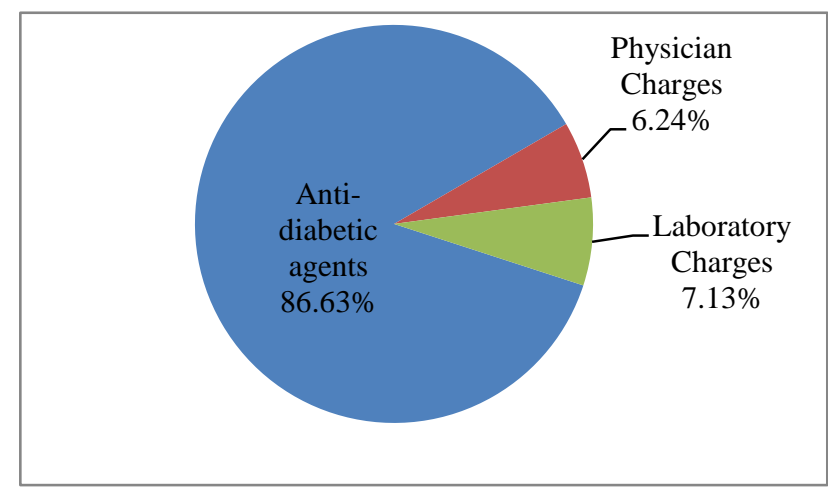

Figure 1: Percentage contribution to average total direct cost.

\section{DISCUSSION}

\section{Drug utilization}

Drug utilization study is a continuing process of reviewing, analysing and interpreting the pattern of drug use, so as to better understand the drug prescribing practices in the institute being studied. It helps to identify the problems that arise from the drug usage and the improvements or changes needed to prevent irrational use of drugs.
In present study, WHO drug use indicators were analysed from prescriptions of all 273 patients. Prevalence of diabetes was seen to be more in males $(54.21 \%)$ than females $(45.79 \%)$, as seen in a number of other studies and in a study done earlier in the same institute by Dutta $S$ et al. ${ }^{15-20}$

As per WHO, average number of drugs per prescription should be in the range of 1.6 to 1.8 drugs. ${ }^{21}$ Present study states 2.95 drugs per prescription, more than that recommended by WHO and more than in a similar study by Sutharson L et al (1.95). ${ }^{22}$ This is probably due to associated co-morbid conditions seen in a number of patients. Also, each active ingredient in an FDC was considered as separate entity in this study. However, the average number of drugs per prescription was much better than other similar studies (3-5 drugs per prescription). ${ }^{16,18,23}$ In a similar study done earlier in the same institute, the number of drugs per prescription was 3.99, much more than in present study. ${ }^{20}$ This change could be the impact of the earlier study in the same institute that would have helped identify the problems and irrational use of drugs. The average number of antidiabetic drugs prescribed was 1.81 per encounter, as in the study by Alex et al. (1.81), and slightly more than the study by Kannan et al (1.4), Agarwal et al (1.4) and Kumar R et al (1.42), and lesser than the study by Dutta et al (2.13) and Acharya et al (2.16). ${ }^{15,16,19,20,24,25}$ However, if 
an FDC were counted as one drug (each active ingredients not counted as separate entity) as per WHO guidelines, the average number of anti-diabetic drugs per prescription would be much lesser (1.08).

Metformin was the most common drug prescribed as monotherapy, and even as a part of combination therapy. These findings were similar to several other studies and also in the study by Dutta $S$ et al. ${ }^{15,18,20,23,25,26}$ The American Diabetes Association (ADA) and European Association for the Study of Diabetes (EASD) guidelines also endorses metformin as first line drug for treatment of T2DM, as metformin is associated with very low risk of hypoglycemia, does not cause weight gain rather may promote weight loss, has beneficial effects on lipid profile, and has low cost. ${ }^{27,28}$ Thiazolidinedione's (Pioglitazone) were the least prescribed, probably because of more adverse effects of weight gain, higher risk of edema, fractures and heart failure. ${ }^{28}$ Newer drug sitagliptin is increasingly being prescribed in comparison to earlier studies, although as a part of combination therapy. ${ }^{15,23}$ Sitagliptin is associated with very low risk of hypoglycemia and other side effects in comparison to sulphonylureas as monotherapy and as combination therapy with metformin. ${ }^{28-30}$

Insulins, especially newer insulin analogues were prescribed more in our study and in the study by Agarwal et al, in comparison to the study by Okonta JM et al $(10.7 \%)$ in Nigeria and by Sutharson L et al. ${ }^{15,22,31}$ This is supported by the recent ADA guidelines that recommend initiating insulin therapy (with or without additional agents) in patients with newly diagnosed T2D and markedly symptomatic and/or elevated blood glucose levels or A1C; or if patients with T2D are not achieving glycaemic goals with OADs. ${ }^{28}$

Combination therapy $(215 ; 78.75 \%)$ was the main mode of anti-diabetic therapy in our study, and was also seen in most of the other studies. ${ }^{16,25,26}$ This was in contrast to the earlier study in the same institute where monotherapy $(63.07 \%)$ was the main mode of therapy. ${ }^{20}$ FDC's were prescribed to $194(71.06 \%)$ patients. An FDC helps in improving the compliance and may also decrease the cost of treatment, although they may increase the chances of adverse drug reactions and drug interactions. ${ }^{32}$ In the current study, the most common combination prescribed was of metformin and glimepiride (76), also the most favoured combination seen in a number of other studies. $^{15,23,25}$

$10.88 \%$ (32) of the anti-diabetic drug formulations were prescribed by generic name, much lower than the WHO standards of generic prescribing $(100 \%){ }^{21}$ This is in contrast to earlier study in the same institute where all drugs were prescribed by brand name, also in a number of other studies. ${ }^{16,20,24}$ Prescription of drugs by generic names helps decrease the cost of the drug therapy. $27.21 \%$ (80) of anti-diabetic formulations prescribed were from NLEM, 2015 and 64 from WHO-EML 2015, which were less than a number of other studies. ${ }^{15,16,20,23}$ These could be because in those studies each ingredient in multidrug formulations was counted separately even for essential medicines. More number of drugs should be prescribed from the essential medicines list as it reduces the cost of therapy.

\section{Pharmacoeconomic evaluation}

CEA is one of the most commonly applied forms of economic analysis in drug therapy. It helps to determine the cost variation between different therapies with similar outcomes in a particular therapeutic area. India being the diabetes capital of the world, plus the chronic nature of diabetes leads to the cost associated with the disease being enormous. The high cost of medications can influence the compliance of the patients and lead to deterioration of his medical health and quality of life. ${ }^{33}$ Reduction in the cost of therapy to the diabetic patients would also help greatly decrease the health spending of India. The main purpose of pharmacoeconomic evaluation is not to directly alter the therapeutic decisions of the physicians, but to help the physicians, pharmacists and policy makers to make informed decisions about whether the cost and extra benefits of the new drug are meaningful within the given budget. $^{34}$

The maximum mean reduction of FBG in this study was seen with FDC of regular insulin and isophane insulin (54.8), similar to a study by Abdulganiyu G. et al. ${ }^{35}$ There are very few similar studies in the literature and more are on oral anti-diabetics. Maximum reduction of FBG in this study by an OHA was seen with FDC of glimepiride and metformin (35.78) and the lowest with pioglitazone (21.85). A study by Abdelaziz MSL et al. on OHAs stated highest reduction in random blood sugar (RBS) with voglibose (172), however in this study voglibose showed much lesser effect on reduction in FBS (22.01). The RBS reduction with glimepiride and metformin (82.52) was also higher than in our study. ${ }^{36}$ This could be due to variation in duration of therapy and the effect on RBS and FBS in these two studies.

Large variation in average cost per unit reduction in FBG (ACER) of anti-diabetes drug therapies prescribed (range from 10.46 to 217.38 ) was seen, similar to the variation seen in an earlier study by Acharya et al sulphonylurea and biguanides combination were seen to be most costeffective. ${ }^{16}$ The most cost effective was combination of glipizide and metformin, however in the earlier studies the most cost-effective was combination of metformin and glimepiride, and monotherapy with metformin. ${ }^{36,26}$ Among the injectable, the FDC of regular insulin and isophane insulin was most cost-effective, as was seen in an earlier study. ${ }^{35}$ OHAs were more cost effective in comparison to insulin's.

The average total direct cost for one month management on OPD basis was INR 1122.2 \pm 1372.53 , more than in the study by Acharya et al (INR 354.60 \pm 305.72 ), as present 
study also included insulin therapy which added substantially to the mean cost of therapy. ${ }^{16}$ The maximum expenditure was on anti-diabetic agents $(86.63 \%)$, also was seen in an earlier study by Grover et al. ${ }^{37}$ Insulin therapy was seen to increase the cost of anti-diabetic therapy many folds.

The cost of drugs may vary if the drugs are generic or branded, or of a different brand as the same drug is manufactured by large number of companies. In India, drug prices are kept under control by the National pharmaceutical pricing authority (NPPA), under the Ministry of chemicals and fertilizers, Government of India. It fixes the ceiling prices of controlled drugs and formulations and is responsible to implement and enforce the prices of the medicines in India, as per the drugs prices control order (DPCO) 2013, an order issued by the Indian government. The pharmaceutical companies cannot sell any medicine above the ceiling price given in the DPCO. ${ }^{38}$ However, only around $18 \%$ of all medicines are under price control. ${ }^{39}$

The cost of treatment of diabetes is huge. The government should bring prices of all drugs used in chronic diseases within affordable range to the common man. Also, more competition in the pharmaceutical market, and increasing the prescriptions of generic drugs would help reduce the cost of therapy. If information about cost effectiveness analysis is readily available to the physicians and pharmacists, it can also help reduce the prescription cost to the patients. ${ }^{40-42}$

Use of incremental cost effectiveness ratio (ICER) in place of ACER would have provided better information of CEA; HbA1c in place of FBG is a better predictor of glycaemic control; and longer duration of follow up would have proved more useful as the anti-diabetic drugs have maximum benefit at 3-6 months.

\section{CONCLUSION}

Rational prescribing has improved as compared to earlier similar study in the same institute with the prescription of generic drugs, lesser number of drugs per prescription. Metformin as monotherapy, and metformin and glimepiride combination therapy were the most commonly prescribed drugs. Among the injectable, insulin degludec and insulin aspart combination were the most prescribed drugs.

CEA concludes that the cost associated with diabetes is huge and varies greatly. The combination therapy of glipizide and metformin was the most cost effective. Insulin treatment has substantial impact on the direct medical costs of diabetes mellitus.

Funding: No funding sources

Conflict of interest: None declared

Ethical approval: The study was approved by the Institutional Ethics Committee

\section{REFERENCES}

1. World Health Organization. Diabetes fact sheet $\mathrm{N}$ 312. Available at http:// www.who.int /mediacentre/factsheets/fs312/en/index.html.

Accessed on 15 May 2016.

2. Powers AC. Diabetes mellitus. In: Kasper DL, Fauci AS, Longo DL, Braunwald E, Hauser SL, Jameson JL, Loscalzo J, eds. Harrison's Principles of Internal Medicine. $17^{\text {th }}$ ed. New York: McGrawHill;2008:2275-2279.

3. World health organization. What is drug utilization research and why is it needed? In: Introduction to drug utilization research. Chapter 1. Geneva: World Health Organization; 2003:8-12.

4. Einarson TR, Bergman U, Wiholm BE. Principles and practice of pharmacoepidemiology. In: Speight TM, Holford NMG, eds. Avery's drug treatment. $4^{\text {th }}$ ed. Auckland: Adis international;1996:371-92.

5. Hogan P, Dall T, Nikolov P. Economic costs of diabetes in the US in 2002. Diabetes Care. 2003;26:917-32.

6. Haycox A, Boland A, Walley T. Basics of economics, health economics and pharmacoeconomics. In: Walley $\mathrm{T}$, Haycox A, Boland A, eds. Pharmacoeconomics. Edinburgh: Churchill Livingstone;2004:1-16.

7. Townsend RH. Post marketing drug research and development. Drug Intell Clin Pharm. 1987;21:1346.

8. Trask LS. Pharmacoeconomics: principles, methods, and applications. In: Dipiro JT, Talbert RL, Yee GC, Matzke GR, Wells BG, Posey L, eds. Pharmacotherapy: a pathophysiologic approach. $8^{\text {th }}$ ed. New York:McGraw-Hill Global Education Holdings;2011. Available at: http://accesspharmacy.mhmedical.com/content.aspx ?bookid $=462 \&$ Sectionid $=41100767$. Accessed 26 April 2016.

9. Scaria S, Raju R, Joseph S, Mohan A, Nair AA. Pharmacoeconomics: principles, methods and indian scenario. Int J Pharm Sci Rev Res. 2015;34(1):3746.

10. World health organization. How to investigate drug use in health facilities: Selected drug use indicators. Geneva: WHO/DAP 1993;1:1-87.

11. WHO Model List of Essential Medicines. Available at http: //www.who.int /medicines /publications/essentialmedicines/en/index.html. Accessed on 9 March 2016.

12. National List of Essential Medicines of India, 2015. Available at http: //cdsco.nic.in /WriteReadData/NLEM-2015/NLEM, \%202015.pdf. Accessed on 9 March 2016.

13. Mishra L (ed). Drug today: Ready reckoner of current medical formulations. Lorina Publications (India) Inc. New Delhi.Oct-Dec 2015.

14. Current index of medical specialities. UBM Medica India Private Limited. 2016;132:479-87.

15. Agarwal AA, Jadhav PR, Deshmukh YA. Prescribing pattern and efficacy of anti-diabetic drugs in maintaining optimal glycemic levels in 
diabetic patients. J Basic Clin Pharma. 2014;5:7983.

16. Acharya KG, Shah KN, Solanki ND, Rana DA. Evaluation of antidiabetic prescriptions, cost and adherence to treatment guidelines: a prospective, cross-sectional study at a tertiary care teaching hospital. J Basic Clin Pharma. 2013;4:82-7.

17. Shahir AQ, Kauser S, Gupta D, Ahmed AN. Prescribing patterns of anti-diabetic medications in a tertiary care teaching hospital, Barilley, UP. India J Pharm Sci Innov. 2013;2(1):41-6.

18. Dashputra AV, Badwaik RT, Borkar AS, Date AP, Kalnawat NR. Pattern of antidiabetic drugs used in outpatient and hospitalized patients in a tertiary health institute of central India. J Cont Med A Dent. 2014;2(3):48-54.

19. Kannan, Arshad, Kumar S. A study on drug utilization of oral hypoglycemic agents in type-2 diabetic patients. Asian J Pharm Clin Res. 2011;4(4):60-4.

20. Dutta S, Beg MA, Anjoom M, Varma A, Bawa S. Study of prescribing pattern in diabetes mellitus patients in a tertiary care teaching hospital at Dehradun, Uttarakhand. Int J Med Sci Public Health. 2014;3:1351-4.

21. Isah AO, Ross-Degnan D, Quick J, Laing R, Mabadeje AFB. The development of standard values for the WHO drug use prescribing indicators. ICUM/EDM/WHO.Available at http:// archives.who.int /prduc2004/rducd /ICIUM_Posters /1a2_txt.htm. Accessed on 12 May 2016.

22. Sutharson L, Hariharan RS, Vamsadhara C. Drug utilization study in diabetology outpatient setting of a tertiary hospital. Indian J Pharmacol. 2003;35:23740 .

23. Sharma P, Sharma N, Parakh R, Sharma N, Gautam $\mathrm{B}$, Motiwale S. Screening of prescriptions in patients of type-2 diabetes mellitus in a tertiary care teaching hospital. Int $\mathbf{J}$ Pharmaceutical Res Bio-Sci. 2014;3(1):401-9.

24. Kumar R, Kohli K, Kajal HL. A study of drug prescribing pattern and cost analysis among diabetic patients in a tertiary care teaching institute in north India. J Drug Delivery Therap. 2013;3(2):56-61.

25. Alex SM, Sreelekshmi BS, Smitha S, Jiji KN, Menon AS, Devi UP. Drug utilization pattern of anti-diabetic drugs among diabetic outpatients in a tertiary care hospital. Asian J Pharm Clin Res. 2015;8(2):144-6.

26. George N, Kumar PVA, Amma VS. Glycemic control and cost effectiveness attained by the drug utilization of oral antidiabetic agents in a tertiary care hospital in South India. Int $\mathbf{J}$ Basic Clin Pharmacol. 2016;5:684-91.

27. Inzucchi SE, Bergenstal RM, Buse JB. Management of hyperglycaemia in type 2 diabetes: a patientcentered approach. position statement of the American diabetes association (ADA) and the
European association for the study of diabetes (EASD). Diabetologia. 2012;55:1577-96.

28. Approaches to glycemic treatment. American Diabetes Association. Diab Care. 2016;39(1):52-9.

29. Bennett WL, Wilson LM, Bolen S, Maruthur N, Singh S, Chatterjee R, et al. Oral diabetes medications for adults with type 2 diabetes: an update. comparative effectiveness review. (Prepared by Johns Hopkins evidence-based practice center under contract no. 290-02-0018.) AHRQ publication no. agency for healthcare research and quality. March 2011

30. Arechavaleta R, Seck T, Chen Y, Krobot KJ, Neill EA, Duran L, et al. Efficacy and safety of treatment with sitagliptin or glimepiride in patients with type 2 diabetes inadequately controlled on metformin monotherapy: a randomized, double-blind, noninferiority trial. Diabetes Obes Metab. 2011;13(2):160-8.

31. Okonta JM, Nduka SO, Idodo VE. Prescribing pattern of antihypertensive and antidiabetic agents in a secondary healthcare institution in Nigeria. $\mathbf{J}$ Pharm Sci Res. 2013;5(1):12-7.

32. Bell DS. Combine and conquer: advantages and disadvantages of fixed-dose combination therapy. Diabetes Obes Metab. 2013;15(4):291-300.

33. Shankar PR. Compliance and rational use of drugs. Drug Inform Bull. 2004;2:1-2.

34. Rachael F. An introduction to health economics. Pharm J. 2003;271:679-81.

35. Abdulganiyu G, Fola T. Cost-effectiveness analysis of anti-diabetic therapy in a university teaching hospital. Int J Pharm Sci Research. 2014;5(3):82-91.

36. Abdelaziz MSL, Rani SH, Ravindranath S, Shaik R, Kasim M, Salam AA. Pharmacoeconomic evaluation of oral-hypoglycemic agents at hospital in Bangalore. J Pharm Bio Sci. 2015;10(5):46-50.

37. Grover S, Avasthi A, Bhansali A, Chakrabarti S, Kulhara P. Cost of ambulatory care of diabetes mellitus: a study from north India. Postgrad Med J. 2005;81:391-5.

38. Drugs prices control order. 2013. Available at http://www.nppaindia.nic.in/DPCO2013.pdf. Accessed on 13 May 2016.

39. Srinivasan S, Srikrishna T, Aisola M. Pharma price control policy: unrealistic and unfair. economic and political weekly. 2014;49(34):13-5.

40. Roy V, Rewari S. Ambiguous drug pricing: a physician's dilemma. Indian J Pharmacol. 1998;30:404-7.

41. Sarkar PK. A rational drug policy. Indian J Med Ethics. 2004;12:30-5.

42. Voluntary organisation in interest of consumer education (VOICE). a study on availability and prices of medicines in India. 2002. Available at http://www.nppaindia.nic.in/report/voicerep.html. Accessed on 13 May 2016.

Cite this article as: Singh A, Dutta SB, Varma A, Beg MA, Kumar H, Kaur A. A drug utilization and pharmacoeconomic study of anti-diabetic drugs prescribed to type 2 diabetes mellitus patients visiting the medicine out-patient department of a tertiary care hospital of north India. Int J Basic Clin Pharmacol 2016:5:1220-7. 